\title{
O Escadote e a experiência do olhar Breve ensaio sobre a condição da fotografia de teatro
}

Filipe Figueiredo

0 primeiro mito a dissipar sobre "teoria" é a ideia de que podemos actuar sem uma. Não há nenhum modo ateórico de entender a fotografia.

(Bate 2009: 25)

Uma imagem inicial: um escadote e um homem que o observa. A aparente banalidade da situação é rapidamente afastada pelas sucessivas tentativas de subida do escadote. 0 esforço investido é sobre-humano, a coreografia inusitada, inábil. Atraída pela visão do espectáculo, uma transeunte aproxima-

se. Sente-se desconcertada. 0 absurdo da acção choca com a sua concepção "regulada" e "previsivel" da vida. A acção desenrola-se nos sucessivos encontros e desencontros entre estas duas personagens.

1

A convite da produção do espectáculo Escadote, um conjunto de fotógrafos enquadrado no contexto formativo do Atelier de Lisboa - escola de fotografia e centro de artes visuais (http://www.atelierdelisboa.pt/) - decidiu "olhar" e interpretar a cena. Catarina Loura, Margarida Machado, Rafael Malhado e Ricardo Spencer, com acompanhamento de Filipe Figueiredo, reflectiram acerca do estatuto da imagem fotográfica a partir do evento performativo e construíram um universo de imagens.

A experiência partiu de uma sensibilização para o papel da imagem fotográfica em torno do teatro, das expectativas que em torno dela são criadas e, logo, da função que dela se espera. A discussão teve por base questões como: o que é uma boa fotografia de teatro? Como responder ao convite lançado pela produção? Como desenvolver um trabalho que dignifique a dimensão autoral e projectual que caracteriza o perfil de formação do Atelier de Lisboa?

Ao longo do trabalho de edição do imenso portefólio produzido, e de que se destacam agora algumas imagens ${ }^{2}$,tornaram-se evidentes os principais desafios colocados aos fotógrafos. São antes de mais problemas técnicos que determinam a escolha de objectivas ou opções de sensibilidade no material fotográfico em função dos recursos de luz. Mas são também opções de outra ordem, que respeitam um determinado programa do olhar. Já defronte da cena, emerge o problema da relação com os actores, a aceitação da sua presença e a sua integração a ponto de se tornarem transparentes sem interferir, com o seu trabalho, no trabalho daqueles. Conquistada a confiança da equipa criativa, o desafio é o da escolha do momento e do ponto de vista de onde fotografar, reconhecer e assumir a condição do olhar.

Todas estas decisões configuram um quadro bem mais complexo do que simplesmente registar o que se passa com uma suposta neutralidade atribuída ainda, por vezes, à fotografia. As próprias escolhas técnicas, como diz Bate (2009: 25), assumem o valor de uma "teoria prática" que, como tal, importa questionar e dela adquirir consciência.

0 momento em que se desenvolveu este trabalho corresponde à fase de ensaios finais. A luz estava feita e o guarda-roupa vestido. Os adereços, simples e determinantes na acção, estavam presentes e operacionais. Afinavam-se os movimentos dos corpos num diálogo permanente entre si. Preparava-se a estreia a menos de uma semana. 0 trabalho de dramaturgia e encenação estava fechado, depois de um processo criativo caracterizado pelo "intercalar de um trabalho de natureza
Tradução livre. No original: "The first myth to dispel about "theory" is the idea that we can do without it. There is no untheoretical way to see photography".

${ }^{2}$ Embora todo o trabalho fotográfico tenha sido feito a cores, valorizando um dos aspectos mais vincados da plasticidade do espectáculo, por condicionalismo da presente edição, as imagens apresentadas estão convertidas para preto \& branco.

Filipe Figueiredo é doutorando em Estudos de Teatro na Faculdade de Letras da Universidade de Lisboa (Bolseiro FCT) e investigador no Centro de Estudos de Teatro da mesma Universidade (CET/FLUL). 

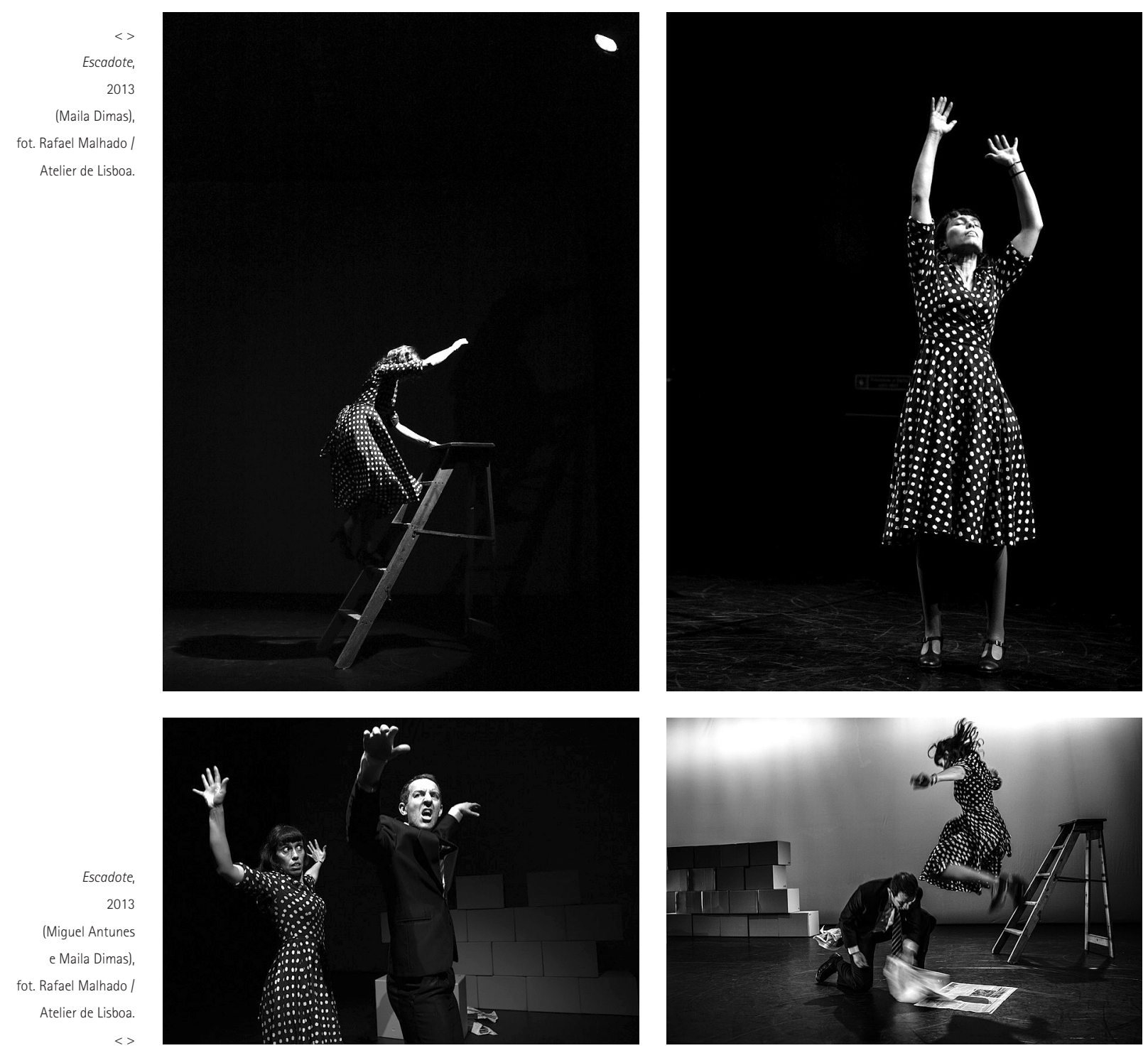

essencialmente contínua com periodos curtos de maior intensidade, realizados - preferencialmente - num contexto de residência artística"(AA.W.b). Por conseguinte, aos fotógrafos, não coube aqui qualquer papel de intervenção no processo criativo do espectáculo. Poder-se-ia dizer que "chegaram tarde", não por vontade própria, mas porque, como na maior parte dos casos se pode constatar, o seu trabalho não é considerado no processo de construção do espectáculo, apesar do acolhimento favorável por parte da produção. Convocados no termo da produção, inconscientemente pesa-Ihes a responsabilidade de "documentar", reproduzir o espectáculo de modo directamente reconhecivel. Contudo, do seu olhar resulta um outro objecto que nunca será o espectáculo, mas que dele preservará uma certa memória e contribuirá para o evocar visualmente.

Autor de uma obra hoje reconhecida, João Tuna dizia em 2003 que a fotografia só Ihe interessa "enquanto representação de ficções"(Melo et al. 2003) e é disso que se trata quando nos confrontamos com as fotografias de teatro: não são o teatro congelado numa fracção de segundos, são representações cujo ponto de partida é o espectáculo de teatro. Já no século XIX, um novo regime dependente das condicionantes da percepção levaram

Goethe a instituir a ideia de "verdade óptica", validando assim a complexidade dos mecanismos da recepção e a sua dimensão subjectiva. A ideia de construção de uma realidade através das imagens fotográficas paira assim como fundamental quando confrontados com as fotografias de teatro. A proximidade que apesar de tudo resulta entre as fotografias e a realidade que Ihes deu origem, leia-se aqui, entre as fotografias do teatro e 0 espectáculo, pode ser, contudo, tão enganadora quanto o universo das imagens parecia a Platão, promovendo a sua desconfiança. A intensificação dos contrastes e da saturação, as variações do valores cromáticos, a alteração na percepção da relação de planos, já para não falar na conversão para o preto e branco que aqui se verifica, são ingredientes mais do que suficientes para assumir a construção de uma visão distinta da realidade do próprio espectáculo.

Assumido como "comédia física, onde a palavra cede em benefício da música e da 'dança' [...] desenvolvendo um 'teatro com efeito de dança" (AA.W.a) e explorando fortemente uma dimensão cromática, o Escadote ofereciase como um terreno apetecivel ao olhar do espectador e 

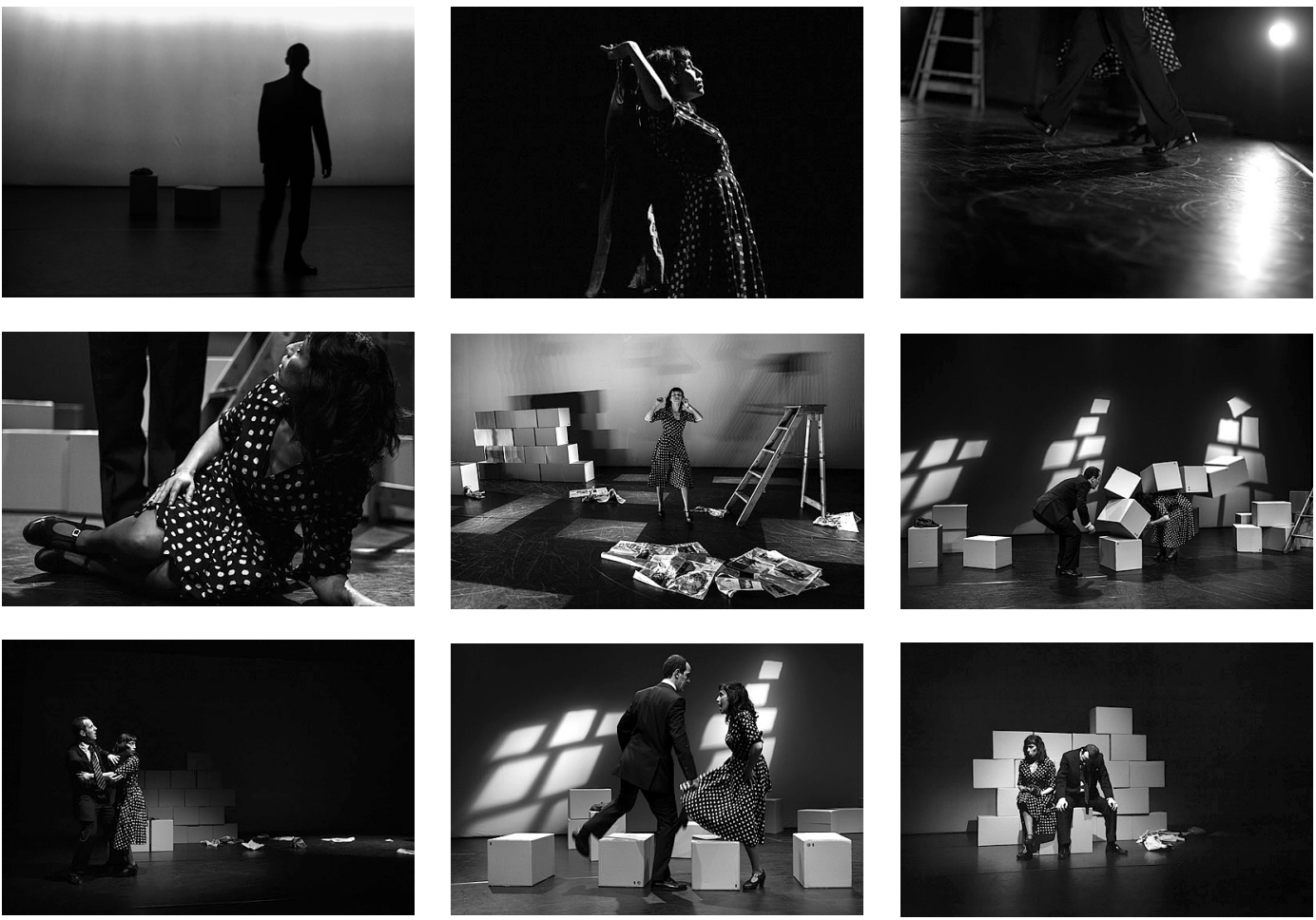

Fot. Filipe Figueiredo Atelier de Lisboa.

Fot. Catarina Loura / Atelier de Lisboa. $<>$

$<<$ fot. Margarida Machado / Atelier de Lisboa.

fot. Rafael Malhado / Atelier de Lisboa. $<>$

fot. Ricardo Spencer / Atelier de Lisboa. $<<<>$ particularmente do fotógrafo. Os criadores do Escadote apresentavam-no como "um espectáculo sem palavras, onde nos deparávamos com questões sobre a livre escolha e o condicionamento do indivíduo em tempos de possibilidades infinitas"(AA.W.a). Também essa é a dificuldade do fotógrafo, que olha em tempo real para a cena e a luz, e procura traduzir o seu espírito na imagem que produz, obrigando-se, assim, a questionar a correspondência que as suas imagens conseguem manter com o espectáculo de que partiram e de que forma este pode ser revisitado naquelas. Fotógrafos diferentes que são, com experiências e equipamentos distintos, detentores de uma techne diferente, embora fixem nas suas imagens momentos semelhantes, evidenciam um olhar particular, esboçando, ainda que de forma tímida, um universo autoral próprio.

A dimensão pantomímica da acção que se desenvolve a partir de quadros enleados por uma trama de movimentos, lembrando, de algum modo, a técnica dramatúrgica de Diderot, assente na ideia dos tableaux, proporciona antes de mais um sentido imagético de grande apuramento. Ainda, a identificação de situações como quadros favorece a atenção do fotógrafo em determinados momentos da acção, propiciando resultados de alguma forma próximos entre os vários autores, como se pôde verificar nos trabalhos de edição. Não obstante isso, reconhecem-se igualmente respostas distintas ao estímulo que é a representação e que resultaram em modos de fotografar diferenciados. Pode dizer-se que o olhar vacila entre a tentação da cena inteira e o risco do corte nos enquadramentos mais fechados e mais atentos às expressões e aos detalhes, assumindo por completo a cesura que o acto fotográfico desde logo implica. É comum ouvir-se os fotógrafos relatar que, a par das fotografias que os directores das companhias e outros agentes seleccionam, mantêm um conjunto de imagens "não eleitas", mas nas quais mais se revêem. Não são menos verdadeiras ou mais falsas do que aquelas, apenas estabelecem uma ligação, à primeira vista, menos evidente.

Sem dúvida que o mito da transparência da fotografia é o primeiro a ser convocado ao olhar estas imagens e que, desde logo, se impõe a vontade de perscrutar nelas a memória do evento. Mas a construção - pois é disso sempre que se trata - que os fotógrafos fizeram a partir do espectáculo, procura de algum modo evidenciar um estatuto de autonomia destas fotografias. Não se trata de negar a realidade do espectáculo nestas imagens, mas tão só de afirmar que elas não são o espectáculo em si, mas objectos que se the referem e operam com um programa autónomo.

Titulo: Escadote (2013). Autores: Miguel Antunes e Maila Dimas. Encenação e Interpretação: Miguel Antunes e Maila Dimas. Música original: Ricardo Freitas. Luz: Nuno Patinho. Apoio à dramaturgia: Caroline Bergeron. Produção executiva: Gi Carvalho. Imagem e edição: António Pedro. Fotografia: Atelier de Lisboa. Local e data de estreia: Black Box do Centro Cultural de Bélem / Fábrica das Artes, Lisboa, 26 de Janeiro de 2013.

\section{Referências bibliogáficas}

BATE, David (2009), Photography: The Key Concepts, Oxford / New York, Berg.

MELO, Jorge Silva / FERREIRA, António Pedro / TOMÁS, Carla Carvalho, et al. (2003), "Fotografar teatro", in Artistas Unidos - Revista, n. 9, 98133.

\section{Sitiografia}

AA.W.(a). Escadote http://ppl.com.pt/pt/prj/escadote

AA.W.(b). Escadote - uma comédia fisica, um espectáculo onde a palavra cede em beneficio da música e da dança. http://escadote.wordpress.com/ 